\title{
The Independent Payment Advisory Board: impact on neurointerventionalists
}

\author{
Laxmaiah Manchikanti, ${ }^{1}$ Joshua A Hirsch ${ }^{2}$
}

${ }^{1}$ Pain Management Center of Paducah, Paducah, Kentucky, USA

${ }^{2}$ Neurolnterventional Radiology, Massachusetts General Hospital, Boston, Massachusetts, USA

\section{Correspondence to} Dr Laxmaiah Manchikanti, Pain Management Center of Paducah, 2831 Lone Oak Road 42003, Paducah, Kentucky, USA; drlm@thepainmd.com

Received 12 September 2011 Accepted 18 September 2011 Published Online First 11 October 2011

\section{ABSTRACT}

The Independent Payment Advisory Board (IPAB) is a powerful component of the Affordable Care Act, with the authority to issue recommendations to reduce the growth in Medicare spending and to provide recommendations to Congress for fast-track implementation. The IPAB works by recommending policies to Congress to help Medicare provide better care at a lower cost, including ideas on coordinating care, getting rid of waste in the system, providing incentives for best practices and prioritizing primary care. Congress then has the power to accept or reject these recommendations. However, Congress faces extreme limitations either to enact policies that achieve equivalent savings or to let the Secretary of Health and Human Services (HHS) follow the IPAB's recommendations. The IPAB statute sets target growth rates for Medicare spending. The applicable percentage for maximum savings appears to be $0.5 \%$ for $2015,1 \%$ for 2016, 1.25\% for 2017 and 1.5\% for 2018 and later. The IPAB Medicare proposal process involves mandatory recommendations and advisory recommendations with multiple reporting requirements. We believe neurointerventionalists, as highly specialized physicians reliant on expensive technology, should be aware of the IPAB and its impact on the practice of medicine.

\section{INTRODUCTION}

$\mathrm{IPAB}$ is an acronym for the Independent Payment Advisory Board, a powerful component of the President's healthcare reform law. It has the authority to issue recommendations to reduce the growth in Medicare spending and to provide recommendations to Congress for fast-track implementation. ${ }^{1-3}$ Certain components of the Patient Protection and Affordable Care Act (ACA) are expected to tackle Medicare fraud and excessive payments for prescription drugs, to propose a stronger federal-state partnership in Medicaid and to include a series of healthcare reforms that would save $\$ 340$ billion by 2021, $\$ 480$ billion by 2023 and at least an additional \$1 trillion in the following decade. One of the keys to these savings is the proposal to strengthen the IPAB, which works by recommending policies to Congress to help Medicare provide better care at lower costs, including ideas on coordinating care, getting rid of waste in the system, providing incentives for best practices and prioritizing primary care. Congress then has the power to accept or reject these recommendations. If Congress rejects the recommendations and Medicare spending exceeds specific targets, Congress must either enact policies that achieve equivalent savings or let the Secretary of
Health and Human Services (HHS) follow the IPAB's recommendations.

\section{HISTORICAL ASPECTS}

A major impetus for healthcare reform has been the rising cost of healthcare programs. ${ }^{4}$ The growth of healthcare spending has been exceeding the country's gross domestic product (GDP) growth, resulting in a healthcare sector that makes up a significant share of the overall economy. Healthcare employs 14.3 million; it comprises more than 595000 separate establishments, including physician offices with 616000 physicians, over 6000 hospitals with almost 1 million beds, plus clinical laboratories, nursing homes and home health providers. ${ }^{5}$ Total national health spending was $\$ 2.5$ trillion in 2009, which corresponds to $17.6 \%$ of GDP (figure 1). Of this total, $32 \%$ was from private health insurance, 20\% from Medicare and 15\% from Medicaid. ${ }^{5}$ In addition, health spending is estimated to grow 6.3\% between 2009 and 2019, rising from $17.6 \%$ of GDP in 2009 to $19.6 \%$ of GDP in 2019. ${ }^{6}$ Consequently, under the present scenario, Medicare and other federal health spending will consume nearly $60 \%$ of federal revenues by 2084 . $^{7}$

It has been postulated that the major drivers of the growth in healthcare spending are technology advances and rising prices, followed by health insurance coverage, reimbursement and market power. Finally, a change in demographics is also expected to drive future spending growth. ${ }^{8}$

The historic patterns of growth in overall healthcare spending, and Medicare in particular, are viewed as not being sustainable. ${ }^{8}$ Several proposals have been advanced over the years to create an independent policy-making entity that would be charged with limiting the further growth in Medicare expenditures ${ }^{9}$ and be insulated from special interest and lobbyist influences since these entities would be appointed, rather than elected. Members would serve for extended terms and would be able to make the 'hard decisions' needed to control rising costs.

The Medicare Payment Advisory Commission (MedPAC) was enacted as part of the Balanced Budget Act of 1997 by merging the Prospective Payment Assessment Commission (ProPAC) and the Physician Payment Review Commission as a legislative branch. ${ }^{10}$ The authority of this commission continues to be advisory with 15 appointed members and an annual expenditure of $\$ 13$ million in fiscal year 2011. ${ }^{4}$

However, with all the enthusiasm about reducing the growth of Medicare, Medicare trustees have presented the data that, under the policies of ACA, by 2019 Medicare payment rates will be lower than under Medicaid. ${ }^{11}$ In addition, Rick 
Figure 1 National health spending by payer.

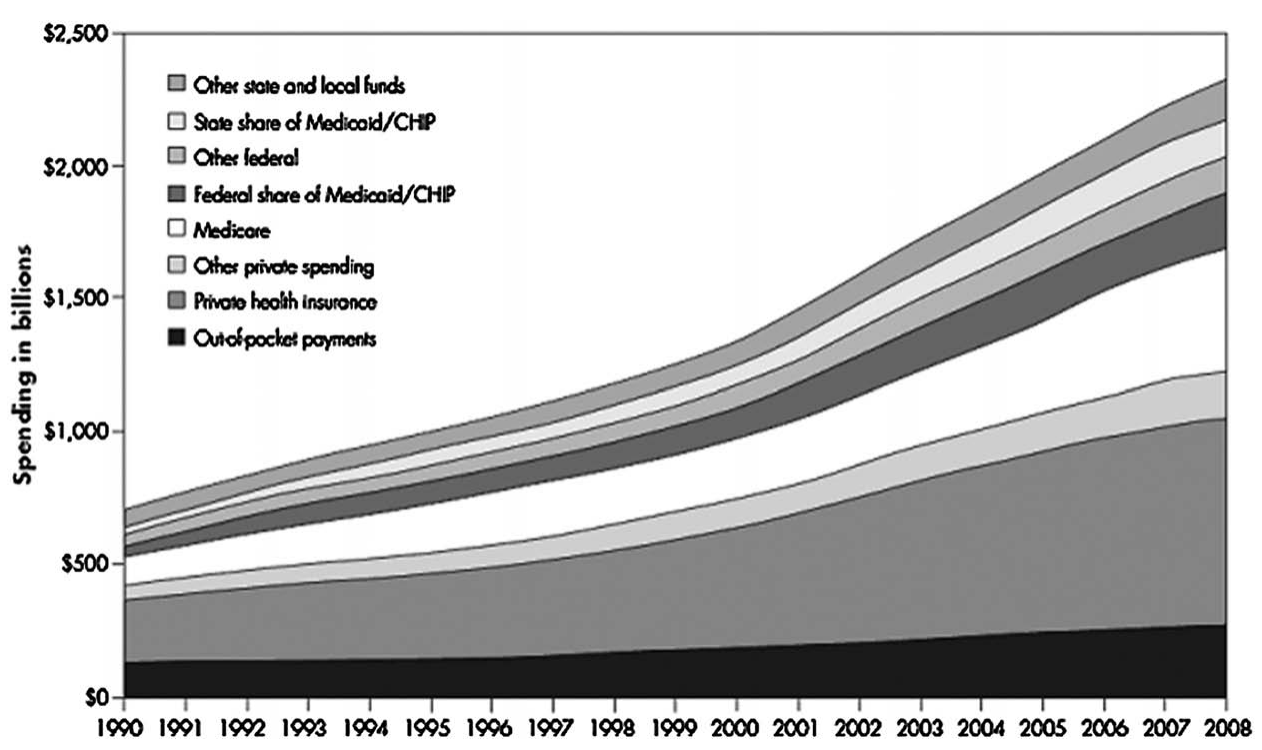

\section{Board membership}

The IPAB is established as an independent board in the executive branch, composed of 15 full-time members appointed by the President and confirmed by the Senate. A majority of members must be non-providers. In contrast to MedPAC commissioners, the board members, as full-time federal employees, cannot engage in any other business, vocation or employment. Former members of the board will be precluded for one year from lobbying before the board, the Department of HHS or any of the relevant committees of jurisdiction of Congress. Appointed members of the board may be removed by the President only for neglect of duty or maleficence in office.

The budget for the board for fiscal year 2012 is \$15 million, only slightly more than MedPAC's budget, with annual adjustments based on increases in the consumer price index (CPI). However, since the IPAB has been described as MedPAC on steroids, modification of MedPAC with an additional budget of $\$ 5$ million may have sufficed.

Key implementation dates of the IPAB are illustrated in table 2.

Table 1 Comparison of the IPAB and MedPAC

\begin{tabular}{|c|c|c|}
\hline Located in & $\begin{array}{l}\text { IPAB } \\
\text { Executive branch }\end{array}$ & $\begin{array}{l}\text { MedPAC } \\
\text { Legislative branch }\end{array}$ \\
\hline Established under & Patient Protection and Affordable Care Act (ACA, P.L. 111-148, § 3403). & $\begin{array}{l}\text { Balanced Budget Act of } 1997 \text { (P.L. 105-33, §4022) by merging Prospective } \\
\text { Payment Assessment Commission (ProPAC) and the Physician Payment } \\
\text { Review Commission (PPRC) }\end{array}$ \\
\hline $\begin{array}{l}\text { Principal statutory } \\
\text { mandate }\end{array}$ & $\begin{array}{l}\text { Make recommendations to be implemented by the Secretary of Health and } \\
\text { Human Services to reduce the per capita rate of growth in Medicare } \\
\text { spending; develop recommendations to slow the growth in national health } \\
\text { expenditures while preserving or enhancing quality of care }\end{array}$ & $\begin{array}{l}\text { Advise Congress on payments to private health plans participating in } \\
\text { Medicare and providers in Medicare's traditional fee-for-service program; } \\
\text { analyze access to care, quality of care and other issues affecting Medicare }\end{array}$ \\
\hline Authority & Board delegated significant policy making authority by Congress & Advisory \\
\hline Size & 15 appointed and 3 ex-officio members & 15 appointed members \\
\hline Term & 6 -year term, staggered & 3-year term, staggered \\
\hline Appointed by & $\begin{array}{l}\text { President in consultation with the majority leader of the Senate, the Speaker } \\
\text { of the House of Representatives, the minority leader of the Senate and the } \\
\text { minority leader of the House of Representatives }\end{array}$ & Comptroller General \\
\hline $\begin{array}{l}\text { Conditions of } \\
\text { employment }\end{array}$ & $\begin{array}{l}\text { Full-time, subject to ethical disclosures, compensation is level II } \\
\text { (Chairperson) and level III (members) of the Executive Schedule, members } \\
\text { may not engage in other business, vocation or employment }\end{array}$ & $\begin{array}{l}\text { Part-time, subject to ethical disclosures, compensation is level IV of the } \\
\text { Executive Schedule (with physician commissioners receiving } \\
\text { a comparability allowance) }\end{array}$ \\
\hline Staff & Executive director and a staff to be determined & Executive director and a full-time staff of 40 \\
\hline $\begin{array}{l}\text { Powers and } \\
\text { work product }\end{array}$ & $\begin{array}{l}\text { Power to hold hearings and obtain official dataAnnual proposals, as } \\
\text { required, annual and biennial reports }\end{array}$ & Power to obtain official dataPublic meetings and two annual reports \\
\hline Budget & $\$ 15$ million in FY2012 updated by the rate of inflation annually & $\$ 13$ million in FY2011 \\
\hline
\end{tabular}

Source: Newman and Davis. ${ }^{4}$

FY, fiscal year; IPAB, Independent Payment Advisory Board; MedPAC, Medicare Payment Advisory Commission. 
Table 2 Key implementation dates with other aspects of the IPAB

\begin{tabular}{|c|c|c|c|}
\hline Providers of services or supplies & Inflationary payment update & Applicable period & Exemption period* \\
\hline Inpatient acute hospitals & Productivity adjustment. Reduction in excess of a reduction due to productivity & Begins FY2012FY2010-FY2019 & Through 12/31/2019 \\
\hline Skilled nursing facilities & Productivity adjustment & Begins FY2012 & None \\
\hline Long-term care hospitals & Productivity adjustment. Reduction in excess of a reduction due to productivity & Begins RY2012RY2010-RY2019 & Through 12/31/2019 \\
\hline Inpatient rehabilitation facilities & Productivity adjustment. Reduction in excess of a reduction due to productivity & Begins FY2012FY2010-FY2019 & Through 12/31/2019 \\
\hline Home health agencies & Productivity adjustment. Annual reduction of $1 \%$ & Begins CY2015CY2011-CY2013 & None \\
\hline Psychiatric hospitals & Productivity adjustment. Reduction in excess of a reduction due to productivity & Begins RY2012RY2010-RY2019 & Through 12/31/2019 \\
\hline Hospice care & Productivity adjustment. Reduction in excess of a reduction due to productivity & Begins FY2013FY2013-FY2019 & Through $12 / 31 / 2019$ \\
\hline Dialysis & Productivity adjustment & Begins CY2012 & None \\
\hline Outpatient Hospitals & Productivity adjustment. Reduction in excess of a reduction due to productivity & Begins CY2012CY2010-CY2019 & Through $12 / 31 / 2019$ \\
\hline Ambulance services & Productivity adjustment & Begins CY2011 & None \\
\hline $\begin{array}{l}\text { Ambulatory surgical } \\
\text { center services }\end{array}$ & Productivity adjustment & Begins CY2011 & None \\
\hline Laboratory services & Productivity adjustment. Reduction in excess of a reduction due to productivity & Begins CY2011CY2011-CY2015 & Through 12/31/2015 \\
\hline Certain durable medical equipment & Productivity adjustment & Begins CY2011 & None \\
\hline $\begin{array}{l}\text { Prosthetic devices, } \\
\text { orthotics and prosthetics }\end{array}$ & Productivity adjustment & Begins CY2011 & None \\
\hline Other items & Productivity adjustment & Begins CY2011 & None \\
\hline
\end{tabular}

\section{Source: Newman and Davis.}

* Since in the first year the chief actuary in the Centers for Medicare and Medicaid Services can potentially make a determination that projected Medicare expenditures exceed the projected target in 2013, the earliest that any board recommendations could be implemented would be August 15, 2014 for the fiscal year beginning in October. Therefore, exemptions are only potentially significant for the period beginning October 1, 2014 through December 31, 2019.

CY, calendar year; FY, fiscal year; IPAB, Independent Payment Advisory Board; RY, rate year.

\section{Medicare spending and savings target}

The statute sets target growth rates for Medicare spending. The target is not a hard cap on Medicare spending growth but, if spending exceeds these targets, the IPAB is required to submit recommendations to reduce Medicare spending by a specified percentage ${ }^{4} 12$ :

For 2015, the applicable percentage (maximum savings) is $0.5 \%$. For 2016, the applicable percentage (maximum savings) is $1.0 \%$. For 2017, the applicable percentage (maximum savings) is $1.25 \%$.

For 2018 and later, the applicable percentage (maximum savings) is $1.5 \%$.

\section{THE IPAB MEDICARE PROPOSAL PROCESS}

The scope of proposals involves mandatory recommendations and advisory recommendations. Further, there are reporting requirements. ${ }^{12}$

\section{Mandatory recommendations}

The IPAB is mandated to submit recommendations whenever Medicare per capita spending growth exceeds statutory targets, according to the deadlines set in law ${ }^{12}$ :

Recommendations related only to Medicare, along with an explanation and rationale for the recommendations.

Recommendations regarding any administrative funding required to implement its proposals.

Certification by the Centers for Medicare and Medicaid Services' (CMS) actuary that, in his opinion, the recommendations will result in savings that are at least equal to the applicable savings target (constrained by the 'applicable limit') and are not expected to result in any increase in Medicare spending over the 10-year period starting with the implementation year. Legislative language that implements the recommendations. The IPAB recommendations are also required to maintain or enhance beneficiary access to quality care.

\section{Advisory recommendations}

The IPAB also has the ability to make advisory recommendations on a much broader range of Medicare and healthcare policy issues and, in some cases, is required to provide such advice. ${ }^{12}$
However, those recommendations-like those of other advisory boards such as MedPAC or typical recommendations of executive branch agencies-are not automatically given the special congressional fast-track consideration.

\section{Limits on the IPAB's authority}

The law includes language that limits the IPAB's scope of authority, prohibiting certain recommendations that could negatively affect beneficiaries and prohibiting recommendations that could affect certain providers. The IPAB is prohibited from including any recommendation that would: (1) ration healthcare; (2) raise revenues or increase Medicare beneficiary premiums or cost sharing; or (3) otherwise restrict benefits or modify eligibility criteria. ${ }^{12}$

\section{Implementation of recommendations and judicial review}

The ACA precludes administrative or judicial review of the Secretary implementing recommendations contained in an IPAB proposal. ${ }^{12}$ The Secretary must implement the IPAB recommendations, or an alternative that has been enacted, by 15 August of the proposal year. If there is no formal congressional action, the Secretary must implement the IPAB's proposal.

\section{CONGRESSIONAL CONSIDERATION OF IPAB PROPOSALS}

\section{Fast-track procedures}

The Congress considers the IPAB's required recommendations under special 'fast-track' procedures set out in the statute. The board's legislative proposal must be introduced by the majority leaders of the House and Senate on the day it is submitted to Congress, and is referred to the appropriate committees. $^{12}$

The committees must report those recommendations, with any changes, in just 2.5 months, no later than April 1 of the proposal year, or the proposals are formally discharged from the committees. The committees and the full House and Senate cannot consider any amendment that would change or repeal the Board's recommendations unless those changes meet the same fiscal criteria under which the Board operates. A vote of three-fifths of members in the Senate ('duly chosen and sworn') is required to waive this restriction. 


\section{Amending and discontinuing the IPAB}

The ACA sets up special procedures for discontinuing the IPAB and its fast-track procedures. ${ }^{12}$ In general it is not in order to 'consider any bill, resolution, amendment, or conference report that would repeal or otherwise change...' the processes for congressional consideration of the IPAB. That provision can be waived in the Senate only with a vote of three-fifths of the members.

Provision is made for a one-time fast-track consideration of a joint resolution to dissolve the IPAB. Such a resolution must be introduced in 2017, no later than February 1 of that year.

\section{Relationships between the IPAB and other entities}

The IPAB is structured to have a strong relationship with HHS and CMS through ex officio board membership, the dominant technical role of the CMS actuary and the Secretary's responsibility to present, comment on and implement the IPAB's recommendations. Theoretically, the IPAB must submit its draft recommendations to MedPAC, as well as to the Secretary, and MedPAC will comment on those recommendations and continue to advise Congress more generally on Medicare policy.

\section{ISSUES RELATED TO THE IPAB}

1. The IPAB is required to submit mandatory recommendations only if Medicare spending is in excess of its statutory target and the medical care component of the consumer price index for all urban consumers (CPI-U) exceeds the CPI-U.

2. Starting with determination year 2018, the CMS actuary must also project the growth in national health spending per capita (for implementation years starting with 2020).

3. The specific statutory targets on per capita growth in Medicare that trigger the IPAB's savings recommendations have been subject to relatively little discussion, but are a central feature of the IPAB's role and authority and the savings attributed to it. Several questions have been raised about these growth targets. ${ }^{12}$

It is well known that any statutory target on Medicare growth, whether imposed by the IPAB or other means, could have negative consequences on the long-term effects of coverage provided to beneficiaries, the adequacy of provider payments, provider participation and beneficiaries' access to needed services. This has been reiterated by the experience with the sustainable growth rate (SGR) formula under Medicare for physician payment, resulting in unintended and negative consequences that were not anticipated when Congress created the formula to limit the volume of physician services. ${ }^{13}$ There is concern that similar problems could emerge in the future if Medicare spending is constrained by a formula set forth in the law that the IPAB is required to recommend and the Secretary to implement.

Importantly for IPAB purposes, the SGR has been considered to yield a budget 'baseline' for physician payments in Medicare that is artificially low, because the Congress is highly likely to continue to prevent such deep cuts. ${ }^{14}$ To account for the baseline problem with the SGR, the law sets an assumption that, in computing the Medicare projection on which IPAB action would be based, the actuary is to assume a $0 \%$ increase in physician payment rates rather than the cuts called for in the statute. This complicates whether and how the IPAB is to deal with physician payments. The actual baseline is whatever is in law, including the negative updates, but the IPAB baseline assumes a freeze. As a technical matter, it is unclear what would happen if the IPAB makes a statutory recommendation to enact a freeze for several years. From the board's baseline perspective, this has no cost, but it clearly has a Congressional Budget Office (CBO) scorable cost.

4. At the enactment of the ACA in March 2010, the CBO estimated that the IPAB would achieve savings of $\$ 15.5$ billion in fiscal years 2015-19. The CBO's most recent Medicare baseline states that the CBO's projections of the rates of growth in spending per beneficiary in the March 2011 baseline are below the target rates of growth for fiscal years 2015-21. As a result, the CBO projects that, under current law, the IPAB mechanism will not affect Medicare spending during the $2011-21$ period. $^{15}$

5. While the requirement to achieve Medicare savings for the implementation year provides a clear direction and target for the board, it may discourage the type of longer-term policy change that could be most important for Medicare and the underlying growth in healthcare costs, including delivery reforms that MedPAC and others have recommended which are included in the ACA — and which generally require several years to achieve savings. ${ }^{12}$

6. There are a number of open questions and debate continues about the IPAB's scope of authority that affects providers, plans and other health industry stakeholders. In addition, even with constraints imposed in the law, questions remain as to the reach of the IPAB with respect to beneficiaries.

7. With the limitations that appear to be imposed on recommendations that would more directly affect beneficiaries, these constraints mean that reductions achieved by the IPAB by 2020 are likely to affect payments related to Medicare Advantage, the Part D prescription drug program and skilled nursing facility services. ${ }^{12}$

8. The Medicare physician payment policy issue under the SGR formula complicates the scope of the IPAB's review of provider payments. Given the artificially low current baseline for physician services and the pattern of annual extensions of the SGR policy for physician payment, it would appear to be very difficult for the IPAB to make mandatory recommendations in this critical area of Medicare payment policy.

9. It is not clear whether the IPAB could adopt a recommendation that would prohibit Medicare supplemental policies from offering first-dollar coverage, as has been suggested by some in the context of current deficit reduction discussions.

10. No one is clear about how the broad prohibition on administrative or judicial review of the Secretary's implementation of IPAB proposals will be interpreted. Congress has on occasion waived judicial review under the Medicare statute for the Secretary's implementation of various components of, for example, a new or revised payment methodology. The waivers tend to apply to specific technical components of that methodology.

\section{IMPLEMENTATION OF BOARD MEDICARE PROPOSALS}

In the absence of limited exceptions, the Secretary implements the board's proposals that relate to payment rate changes on August 15 of the proposal year, which take effect on October 1 and January 1 for Parts $\mathrm{C}$ and $\mathrm{D}$ payment rate changes. ${ }^{4}$

Two general exceptions have been described to implementing a board proposal: if federal legislation was enacted by August 15 of the proposal year that superseded the board's recommendations and beginning with implementation year 2020, and beyond, if a joint resolution was enacted prior to August 15, 2017 to discontinue the board. 


\section{Potential impact of the IPAB}

Qualifications and recruitment of board members

By statute, the board is to be composed of members drawn from a wide range of professions and backgrounds in addition to geography; a majority cannot be individuals directly involved in the provision or management of the delivery of Medicare items and services. ${ }^{4}$ However, it is not clear whether this determination of a member's status is made at the time of nomination or whether a potential nominee's status is a function of their prior experiences.

The stated objective for an independent board was to isolate healthcare payment decisions from the influence of special interests. While the statute specifies the qualifications of board members with nationally recognized expertise, it also specifies that the board should include, among others, employers, thirdparty payers and representatives of consumers and the elderly. In moving beyond expertise, skills and experience, and naming specific groups that should be included on the board, the legislation designates some interests as worthy of being represented and others, by omission, as not being worthy. These efforts, rather than isolating the board from the influence of special interests, appear to welcome some interests directly into the process, and preserve administration goals which are independent of accountability.

\section{Effect of IPAB proposals beyond Medicare}

It is the opinion of the authors that the implications of the IPAB's recommendations will have a broader impact than Medicare alone. Many payers fashion their payments on Medicare rates, such as 'Medicare plus X\%', so recommendations to reduce Medicare payments for certain procedures or suppliers are likely to have a ripple effect throughout the healthcare system and could lead to a reduction in the average price paid for such services or supplies.

\section{CONCLUSION}

One of the rationales for establishing the IPAB was to separate Medicare policy-making from congressional politics. ${ }^{12}$ It is an independent body that can make expert recommendations about Medicare within spending constraints established by Congress in the enabling legislation. It is presumed to make these recommendations without the political pressures that often confront elected officials and with a fast-track congressional review process and default implementation in the absence of congressional action. The Congress, in creating the IPAB, subjected itself to future constraints in the form of the fast-track process, and shifted policy authority to the IPAB and other executive branch officials through both the new authority provided to the IPAB and the explicit constraints and timetable the ACA placed on Congress.

Neurointerventionalists, as providers of specialized healthcare, should be familiar with the facts regarding the IPAB.

Acknowledgments We would like to thank Pain Physician for providing permission to publish in an abbreviated form.

Competing interests None.

Contributors LM and JAH both did research. LM wrote first draft. JH edited and contributed to writing final paper.

Provenance and peer review Not commissioned; internally peer reviewed.

\section{REFERENCES}

1. Public Law No: 111-48: H.R. 3590. Patient Protection and Affordable Care Act 23 March 2010. http://www.gpo.gov/fdsys/pkg/PLAW-111 publ148/pdf/PLAW111publ148.pdf

2. Manchikanti L, Caraway DL, Parr AT, et al. Patient Protection and Affordable Care Act of 2010: reforming health care reform for the new decade. Pain Physician 2011;14:E35-67

3. Manchikanti L, Falco FJE, Singh V, et al. The Independent Payment Advisory Board. Pain Physician 2011;14:E313-42.

4. Newman D, Davis CM. The Independent Payment Advisory Board. CRS Report for Congress. 2010. http://assets.opencrs.com/rpts/R41511 20101130.pdf laccessed 24 Aug 2011).

5. Medicare Payment Advisory Commission. Report to the Congress: Medicare Payment Policy. Washington, DC: Medicare Payment Advisory Commission, 2011.

6. Sisko AM, Truffer CJ, Keehan SP, et al. National health spending projections: the estimated impact of reform through 2019. Health Aff 2010;29:1933-41.

7. Congressional Budget Office. The Long-Term Budget Outlook. Washington, DC: CBO, 2010b.

8. U.S. General Accounting Office. Health Care: Unsustainable Trends. GA0-04793SP. 2004:3. http://www.gao.gov/new.items/d04793sp.pdf laccessed 24 Aug 2011).

9. Terry K. Should MedPAC be Given Authority Over Medicare Payments. BNET, 2009 http://www.bnet.com/blog/healthcare-business/should-medpac-be-given-authorityover-medicare-payments/414 Blog on CBS Interactive Business Network.

10. H.R. 2015. Balanced Budget Act of 1997. P.L. 105-33. House Bill, 5 August 1997.

11. Ferrara P, Hunter L. How ObamaCare guts Medicare. Wall St J 2010.

12. Ebeler J, Neuman T, Cubanski J. The Independent Payment Advisory Board: A New Approach to Controlling Medicare Spending. The Kaiser Family Foundation Program on Medicare Policy, 2011.

13. Manchikanti L, Hirsch JA. Medicare physician payment rules for 2011: a primer for the neurointerventionalist. AJNR Am J Neuroradiol 2011;32:E101-4.

14. Medicare Payment Advisory Commission. Report to the Congress. Medicare and the Health Care Delivery System. Washington, DC: Medicare Payment Advisory Commission, 2011.

15. Congressional Budget Office. March 2011 Medicare Baseline. Washington, DC: Congressional Budget Office, 2011. 